\title{
Narrativas de um "milagre": as transformações bioculturais no Cerrado brasileiro ${ }^{1}$
}

\author{
Narratives of a "miracle": the biocultural transformations in \\ the Brazilian Cerrado \\ Claiton Marcio da Silva* \\ Marlon Brandt ${ }^{* *}$ \\ Delmir José Valentini***
}

\begin{abstract}
Resumo
Este artigo tem por objetivo principal abordar como o Cerrado se tornou o território privilegiado para a expansão da fronteira agrícola no Brasil. Até a Segunda Guerra Mundial considerado enquanto um território dominado por solos ácidos e que, no máximo, apropriado para pastagens, o impulso do Estado brasileiro e de empresas privadas em pesquisas sobre fertilidade dos solos transformou o Cerrado brasileiro em um "celeiro de grãos" e da pecuária moderna em pouco mais de quatro décadas - um "milagre", nas palavras dos defensores do agronegócio. Por outro lado, muitas das práticas tradicionais de fertilização e cultivo foram relegadas. Para esta pesquisa, foram utilizados referenciais bibliográficos e pesquisas de arquivos, principalmente relacionadas aos estudos sobre os solos.
\end{abstract}

Palavras-Chave: Cerrado; Modernização Agropecuária; História Ambiental.

\begin{abstract}
This article aims to address how the Cerrado has become the privileged territory for the expansion of the agricultural frontier in Brazil. Until World War II, considered a territory dominated by acid soils and at most suitable for pasture, the impulse of the Brazilian State and private companies in research on soil fertility transformed the Brazilian Cerrado into a "grain barn" and
\end{abstract}

\footnotetext{
${ }^{1}$ Este artigo é parte dos resultados do projeto "A Era da Soja”, contemplado pela Chamada Universal MCTIC/CNPq n.. 28/2018.

*Doutor em História das Ciências pela Casa de Oswaldo Cruz (COC/Fiocruz). Professor do Programa de Pós-Graduação em História da Universidade Federal da Fronteira Sul. E-mail: claiton@uffs.edu.br

** Doutor em História pela Universidade Federal de Santa Catarina. Professor do Programa de Pós-Graduação em História da Universidade Federal da Fronteira Sul. E-mail: marlon.brandt@uffs.edu.br

*** Doutor em História pela Pontifícia Universidade Católica do Rio Grande do Sul. Professor do Programa de Pós-Graduação em História da Universidade Federal da Fronteira Sul. E-mail: valentini@uffs.edu.br
} 
modern cattle-raising in little more than four decades - a "miracle", in the words of agribusiness advocates. On the other hand, many of the traditional fertilization and cultivation practices have been relegated. For this research, bibliographic references and archive research were used, mainly related to soil research.

Keywords: Cerrado; Agricultural Modernization; Environmental History.

\section{Introdução}

O bioma Cerrado é considerado, principalmente por representantes do agro-hidro-negócio industrial - ou seja, o agronegócio que dispõe de amplo capital e tecnologia sem interesse na sustentabilidade dos recursos naturais -, como a última fronteira agrícola antes da floresta Amazônica para fins de exploração. O local que era em sua grande maioria composto por uma paisagem caracterizada por formações que vão de áreas com vegetação mais densa, os cerradões, além dos cerrados e formações campestres, foram sendo transformado em grandes extensões de terras agricultáveis mediante a modernização da agricultura e dos meios de transporte e circulação, modificando assim muitas de suas características físicas e ecológicas. ${ }^{2}$

Por outro lado, a história do uso do bioma Cerrado contém lições fundamentais para a proteção cultural e ambiental. o que ocorreu no Cerrado, merece destaque pelo fato do impacto antrópico ter atingido velocidade, alcance e escala, raramente observados anteriormente na história da humanidade em outro bioma. Antes da Segunda Guerra Mundial, latifundiários e governantes em geral consideravam as terras do Cerrado inférteis e inadequadas para a agricultura em larga escala. A economia local era movimentada pela atividade de fazendeiros, pequenos agricultores e grupos indígenas, que exploravam a mineração, criavam gado e praticavam a agricultura de subsistência. A partir da aceleração do processo de ocupação, o Cerrado foi marcado para além de sua biodiversidade, incluindo a presença de variados grupos de indígenas, populações tradicionais descendentes dos paulistas atraídos pelo ouro nos séculos XVII e XVIII e comunidades Quilombolas. ${ }^{3}$ Enquanto predominava

\footnotetext{
${ }^{2}$ AB'SABER, Aziz Nacib. Os domínios de natureza no Brasil: potencialidades paisagísticas. 5 ed. São Paulo: Ateliê Editorial, 2008.

${ }^{3}$ GANEN, Roseli Senna; DRUMMOND, José Augusto; FRANCO, José Luiz de Andrade. Conservation Polices and Control of Habitat Fragmentation the Brazilian Cerrado Biome. Ambiente \& Sociedade, vol. 16, no. 3, 2013, pp. 99-118.
} 
a produção animal naquele local, havia crescentes esforços para converter solos ácidos em terras férteis.

Este artigo, portanto, destaca processos de transformações que ocorreram no Cerrado e que provocaram alterações na forma de uso da terra e nas características gerais do bioma. Mais especificamente, visando entender o papel das agências de pesquisas, das instituições, dos programas governamentais e dos grupos sociais locais - que influenciaram nas respostas em torno dos desafios ambientais no bioma Cerrado. Serão elencadas algumas consequências das transformações ambientais que envolvem a degradação da diversidade e as alterações na diversidade biocultural local.

Segundo William Beinart, ${ }^{4}$ o conceito de diversidade biocultural foi possivelmente usado pela primeira vez no início da década de 1990, pelo britânico Darrel Posey em conexão com os seus estudos na América Latina. Posey era etno-entomologista e ativista em prol dos direitos dos povos indígenas e buscava capturar o elo inextricável entre a diversidade biológica e cultural. Motivado a defender os conhecimentos indígenas e tradicionais, argumentava que a biodiversidade só poderia ser conservada se esses grupos fossem protegidos, por causa de seus conhecimentos, habilidades e uma longa experiência histórica, que possibilitavam que os mesmos pudessem viver em certo equilíbrio com a natureza, citando como exemplo, os povos vizinhos na Amazônia.

Segundo Posey, proteger a identidade cultural dos povos indígenas seria a melhor maneira de conservar a biodiversidade. Baseado neste conceito, este artigo aborda como os interesses da agricultura em larga escala, baseada na fertilização química do solo e, por outro lado, a manutenção do ecossistema pelos povos indígenas, entraram em rota de colisão, resultando na degradação progressiva do último.

Ao realizar uma síntese das diferenciações no território brasileiro, Milton Santos e Maria Laura Silveira ${ }^{5}$ propõem uma divisão regional baseada na difusão diferencial do que denominam como meio técnico-científico-informacional (MTCI) e nas heranças do passado. Assim propõe uma divisão, no caso uma sugestão, da existência de quatro Brasis. Seriam eles a região concentrada, onde o MTCI teria maior densidade, formada pelo Sudeste e pelo Sul, a região do Nordeste, da Amazônia e do Centro-Oeste, onde se encontram os Cerrados.

\footnotetext{
${ }^{4}$ BEINART, William. Bio-invasions, Biodiversity, and Biocultural Diversity: Some Problems with These Concepts for Historians. In: MAUCH, Christof; ROBIN, Libby (orgs.). The Edges of Environmental History: Honour- ing Jane Carruthers, RCC Perspectives, 2014, no. 1, pp. 75-80.

${ }^{5}$ SANTOS, Milton. SILVEIRA, Maria Laura. O Brasil: território e sociedade no início do Século XXI. 12 ed. Rio de Janeiro: Record, 2008.
} 
No Cerrado, uma área de ocupação periférica, de certo modo "recente", se considerarmos o impulso dado pela construção da Capital Federal, a abertura das rodovias interligando-a com o restante do país e as modificações na rede urbana a partir da década de $1950,{ }^{6}$ o MTCI se estabeleceu em meio a um território dominado ainda por populações tradicionais, com sua agricultura de subsistência e miúda comercialização local de seus excedentes. Seria sobre essa "herança de rarefação" de pessoas e relações econômicas que se assentariam "os novos dados constitutivos do território", sendo estes "os do mundo da informação, da televisão, de uma rede de cidades assentada sobre uma produção agrícola moderna e suas necessidades relacionais", criando "um espaço inteiramente novo e com grande participação na globalização".?

$\mathrm{Na}$ agricultura que passou a se desenvolver no Cerrado, as inovações técnicas e organizacionais criaram um novo uso no tempo e um novo espaço na terra. A manipulação dos solos, das plantas e dos seus ciclos naturais, bem como a melhoria nas comunicações e a preferência dada à produção de commodities destinados à exportação possibilitaram ao Cerrado a reinvenção da sua natureza. A união entre técnica e ciência, um dos elementos centrais do MTCI, se deu, conforme Milton Santos, sob a égide do mercado. A partir da unificação entre ciência e técnica, o Cerrado se tornou um espaço de produção para uma economia globalizada, demandando uma enorme densidade de mecanização agrícola e emprego de modernas tecnologias. Nesse contexto, "a ideia de ciência, a ideia de tecnologia e a ideia de mercado global devem ser encaradas conjuntamente e desse modo podem oferecer uma nova interpretação à questão ecológica", uma vez "que as mudanças que ocorrem na natureza também se subordinam a essa lógica". ${ }^{8}$

Essa manipulação, encontra-se expressa na paisagem, que pode ser compreendida como "o conjunto das formas que, num dado momento, exprimem as heranças que representam as sucessivas relações entre o homem e a natureza", ${ }^{9}$ reunindo elementos naturais e artificiais do passado e do presente, ou seja, uma acumulação de tempos no espaço. Analisar essa dinâmica implica não somente na descrição do ambiente e do modo de vida dos diferentes sujeitos que ocuparam esse espaço em diferentes tempos, mas também na

\footnotetext{
${ }^{6}$ AB'SABER, op. cit.

${ }^{7}$ SANTOS, Milton. SILVEIRA, Maria Laura. O Brasil: território e sociedade no início do Século XXI. 12 ed. Rio de Janeiro: Record, 2008, p. 271.

${ }^{8}$ SANTOS, Milton. A natureza do espaço. Técnica e tempo, razão e emoção. 4 ed. São Paulo: Edusp, 2006, p. 238.
}

${ }^{9}$ Ibidem, p. 103. 
compreensão, como destaca Paul Claval "as relações complexas que se estabelecem entre os indivíduos e os grupos, o ambiente que eles transformam, as identidades que ali nascem ou se desenvolvem". ${ }^{10}$

No caso do Cerrado, a "cientifização e tecnificação da paisagem"11 está na base da produção, utilização e funcionamento do espaço, suprimindo elementos naturais, realizando modificações e acréscimos, artificializando cada vez mais a paisagem. Um exemplo desse processo é a crescente transformação da composição química dos solos através de um intenso processo de fertilização, construindo o que seria uma "vocação" até então impensável desse solo para a prática agrícola. ${ }^{12}$ Liderado por incentivos governamentais e de instituições privadas, na tentativa de aumentar os experimentos de fertilização e introdução de monoculturas no Cerrado, foram criados uma série de projetos e instituições para a modernização agrícola.

Os defensores do agronegócio vêm lucrando amplamente com os projetos de fertilização e ampliação dos usos do solo. No outro extremo, a maioria dos grupos, formados por indígenas e comunidades tradicionais são forçados a deixar suas terras em função da diminuição da biodiversidade e dos recursos naturais, catalisados pela presença da monocultura, que continua em franca expansão. Desta forma, o Cerrado também se enquadra na categoria dos estudos culturais ambientais, por haver um discurso político e científico, moldando respostas aos desafios ambientais, incluindo as resistências de grupos sociais marginalizados do processo de modernização agrícola.

As agroempresas internacionais e nacionais propõem a padronização biológica do mundo, ${ }^{13}$ as savanas brasileiras ainda apresentam uma imensa diversidade biocultural, baseada nos preceitos do conhecimento tradicional, através da longa relação desses grupos com o meio ambiente. Neste ponto, inspirado na teoria actor-network de Bruno Latour, ${ }^{14}$ é possível perceber que o ambiente do Cerrado também agiu sobre os diferentes grupos humanos, colocando desafios e reagindo às transformações, diante das quais eles continuam resistindo e se moldando.

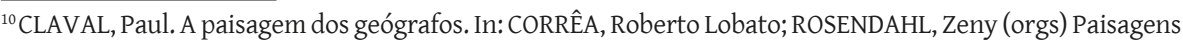
textos e identidade. Rio de Janeiro: EdUERJ, 2004, p. 71.

${ }^{11}$ Ibidem, p. 239.

${ }^{12}$ AB'SABER, op. cit., p. 116.

${ }^{13}$ UEKÖTTER, Frank. Rise, Fall, and Permanence: Issues in the Environmental History of the Global Plantations. In: UEKÖTTER, Frank. Comparing Apples, Oranges, and Cotton: Environmental Histories of the Global Plantation. Campus Verlag gmbH, 2014, pp. 7-26.

${ }^{14}$ LATOUR, Bruno. Reassembling the Social: An Introduction to Actor-Network-Theory. Oxford University Press, 2005.
} 


\section{Apresentando o Cerrado}

Atualmente os biomas brasileiros são distribuídos da seguinte forma: a Amazônia ocupa 49,5\% do território, em seguida, aparecem os biomas do Cerrado (23,3\%), Mata Atlântica (13\%), Caatinga (10,1\%), Pampa (2,3\%) e Pantanal (1,8\%), como podemos observar no mapa 01. O Cerrado, além de ser o segundo maior bioma brasileiro apresenta uma grande variedade de espécies endêmicas, tanto da flora quanto da fauna. ${ }^{15}$

o Bioma Cerrado se caracteriza, fisionomicamente, pela existência de um extrato herbáceo formado basicamente por gramíneas, arbóreos e arbustivo de caráter lenhoso. Tais características de metamorfoses ou alternâncias deste bioma ocorrem devido à relação intrínseca com o nível do lençol freático, com a fertilidade e a composição do solo e da geomorfologia do relevo, paralelamente ao papel das ações dos seres humanos nas alterações e composição deste bioma. ${ }^{16}$

O Cerrado faz fronteira com áreas ocupadas pelas florestas amazônicas ao norte e oeste, com a Caatinga ao nordeste e Mata Atlântica ao leste e ao sul. A planície do Pantanal fica a sudoeste, atingindo áreas que se estendem do Paraguai até Bolívia. O núcleo contínuo do bioma se estende do Equador a $23 \mathrm{~S}$ e de 40 a 55L, como pode ser observado no mapa 01, onde existem algumas manchas descontínuas, cercadas por florestas amazônicas. A área original do Cerrado é de dois milhões de $\mathrm{km}^{2}$, equivalente à área combinada da Espanha, França, Itália e Grã-Bretanha. O bioma é composto por variados tipos de vegetação, alternando a paisagem sem árvores, até florestas mais densas. Cerca de $61 \%$ do bioma Cerrado é composto por savanas, seguidas por florestas $(32 \%)$ e campos $(7 \%){ }^{17}$

\footnotetext{
${ }^{15}$ CARMONA, R.; MARTINS, R. R. e FÁVERO, A. P. Características de sementes de gramíneas nativas do cerrado. Pesq. Agrop. Bras., Brasília, v.34, n.6, p.1069. Jun. 1999. Arquivo virtual in: http://www.scielo.br/ $\mathrm{pdf} / \mathrm{pab} / \mathrm{v} 34 \mathrm{n} 6 / 8409$

${ }^{16}$ RIGONATO, V. D. A dimensão sociocultural das paisagens do cerrado goiano: distrito de Vila Borba. In: ALMEIDA, Maria Geralda (Org.). Tantos cerrados: múltiplas abordagens sobre a biogeodiversidades e singularidade cultural. Goiânia: Editora Vieira, 2005.

${ }^{17}$ CRITICAL ECOSYSTEM PARTNERSHIP FUND. Perfil do ecossistema hotspot de biodiversidade do Cerrado. Critical Ecosystem Partnership Fund, Apr. 2016.
} 
Mapa 01 - Biomas Brasileiros.

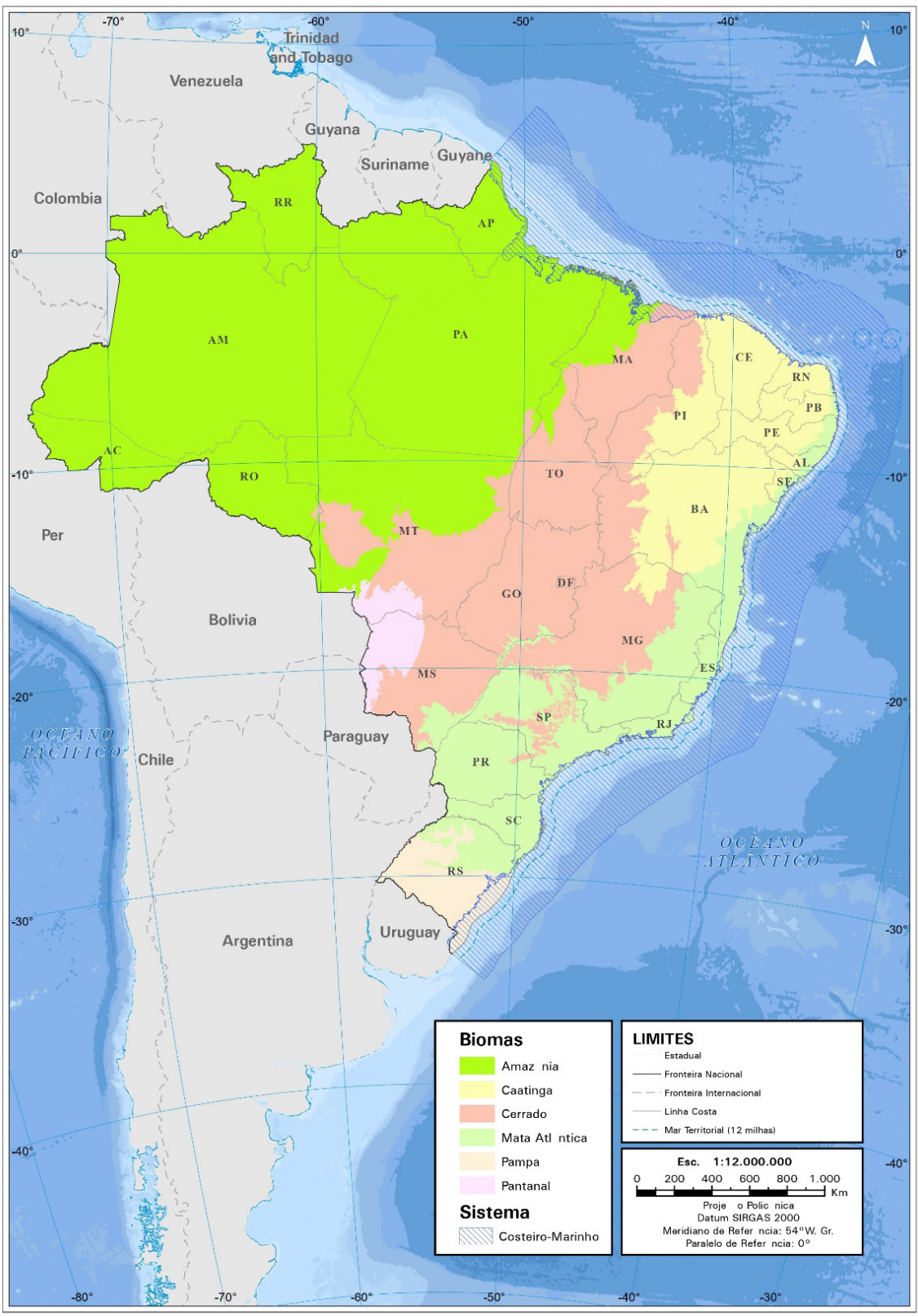

Fonte: Plataforma Geográfica Interativa - Biomas e Sistema Costeiro-Marinho do Brasil. Instituto Brasileiro de Geografia e Estatística. Disponível em: https://www.ibge.gov. br/apps/biomas/. Acesso em julho de 2020. 
Cabe destacar que são hotspots ${ }^{18}$ as áreas consideradas prioritárias para conservação, onde há alta biodiversidade, paralela à ameaçada no mais alto grau. É definida com tal classificação, toda área com pelo menos 1.500 espécies endêmicas de plantas e que tenha perdido mais de três quartos de sua vegetação original. Com toda a variedade apresentada e decorrente do cenário de acelerada alteração da paisagem, fez com que o Cerrado sofresse graves ameaças, o que o colocou na lista dos hotspot do Hemisfério Sul, com pelo menos 345 espécies de plantas ameaçadas de extinção. ${ }^{19}$

Para além das alterações em torno das atividades agrícolas, quarenta e três milhões de pessoas vivem em áreas urbanas e mais de doze milhões habitam as áreas rurais deste bioma. No Centro-Oeste brasileiro, 10\% da população regional é indígena, ${ }^{20}$ dividida entre mais de oitenta grupos étnicos - como os Xavantes, Tapuias, Karajás, Avá-Canoeiros, Krahôs, Xerentes, Xacriabás, assim como os Apinajés e Bakairis - todos eles estabeleceram estratégias historicamente fundamentadas de gestão da biodiversidade e convívio com o bioma local, por milhares de anos.

Atualmente, a ocupação e usos do Bioma do Cerrado é cercada por muitas controvérsias. Enquanto defensores do agronegócio destacam a importância de aumentar a produção agrícola nessas terras, pesquisadores e ambientalistas apontam a degradação ambiental causada pela expansão da fronteira agrícola. Com a introdução da lavoura e o aumento da criação de gado, já no final do século XIX, foram inseridas diferentes espécies de gramíneas no Centro-Oeste. Tais gramíneas, após terem sido aclimatadas, resultaram na brusca alteração de ecossistemas e na homogeneização indiscriminada das pastagens. Além das pastagens exóticas, há outra constante ameaça aos ecossistemas locais na região que são os frequentes incêndios, provocados por proprietários, visando a chamada limpeza do terreno. Ateia-se fogo nas pastagens visando a própria regeneração ou mesmo substituí-las por monoculturas, como é caso da soja e da cana de açúcar.

Outras espécies exóticas vêm sendo introduzidas no Cerrado. Técnicos das empresas Votorantim, Anglo American e do MAPA (Ministério da Agricultura, Pecuária e Abastecimento) vem discutindo a inserção de rodízios

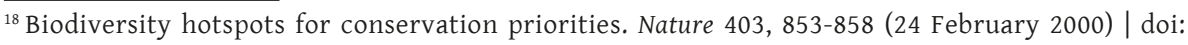
10.1038/35002501;

${ }^{19}$ CRITICAL ECOSYSTEM PARTNERSHIP FUND. Op cit., p. 33. Atualmente, o bioma Cerrado é composto por 12.070 espécies de plantas, 951 espécies de mamíferos, 856 espécies de avifauna e 1.266 espécies de fauna aquática (p. 29).

${ }^{20}$ CODEPLAN. População indígena. Um primeiro olhar sobre o fenômeno do índio urbano na Área Metropolitana de Brasilia. Brasília: Diretoria de Estudos e Políticas Sociais, 2015.
} 
de lavoura, pecuária e silvicultura como sistemas integrados a serem aplicados neste Bioma. Neste sistema, espécies como eucalipto spp, seria consorciado com a pastagem e também com o cultivo de grãos ou forrageiras. ${ }^{21}$ Sendo assim, pode-se elencar, além dos itens citados, outras atividades que compõem as principais ameaças ambientais do bioma Cerrado: a criação de gado, as monoculturas (principalmente os cultivos de soja, milho e algodão), a produção de biocombustível (cana-de-açúcar), a extração de carvão vegetal, a silvicultura (monocultura de exóticas) e o fogo.

\section{A infertilidade em pauta: corrigir para explorar}

A lenda dos Bakairi conhecida como o "Cervo Estúpido" fala da crença de que o Cerrado era composto por solos ácidos demais para suportar uma agricultura e áreas de matas. A lenda foi transcrita pelo etnólogo Karl von den Steinen e publicada originalmente em 1894, refere-se a um episódio em que um cervo encontrou um peixe bagadu (peixe da família Practocephalus) se debatendo nas margens do rio. o cervo devolveu o peixe ao rio e, como sinal de gratidão, o bagadu guiou o cervo à plantação de mandioca e deu-lhe alguns ramos da raiz para que ele pudesse iniciar sua própria plantação. A estupidez do cervo consistiu em acreditar que poderia fazer o plantio da raiz com sucesso, naquele solo. Para que a plantação se concretizasse, primeiro, era necessário queimar as florestas, destruindo o delicado equilíbrio do ecossistema local. O segundo ponto nevrálgico da lenda mostra que, ao consumir indiscriminadamente a raiz, levaria à morte por envenenamento, uma vez que é necessário eliminar o veneno da mandioca para o consumo. Kéri - irmão de Kamé e um dos gêmeos que originaram os povos Bakairi - roubou a mandioca do cervo e aprendeu a extrair o veneno da planta.

A lenda acima mencionada, funciona como pista de que vários grupos sociais consistentemente consideravam os solos dos campos cerrados como uma área marginal para as práticas agrícolas. Essas percepções garantiram a prevalência de que havia a agricultura de subsistência nas regiões. As práticas agrícolas, desde a sedentarizarão na região, eram estabelecidas às margens dos rios e havia, antes da introdução das gramíneas exóticas, bovinos de corte criados em pastagens nativas. Os solos do Cerrado, por sua vez, foram considerados por anos como inférteis, porém, já é de conhecimento que os mesmos sempre ofereceram uma boa estrutura física. O Cerradão, por exemplo, era

\footnotetext{
${ }^{21}$ MORETTO, S. P. Na Fronteira do Cerrado: as transformações ambientais no Norte de Goiás. Revista Eletrônica Expedições: Teoria da História e Historiografia, v. 7, p. 119-130, 2016.
} 
originalmente fértil o suficiente para sustentar a cobertura florestal. ${ }^{22} \mathrm{Na}$ figura 01, pode-se observar as variadas fitofisionomias que compõe o Cerrado e suas diferentes características fisiológicas.

Figura 01 - Fitofisionomia do bioma Cerrado.

\section{FITOFISIONOMIAS DO BIOMA CERRADO}

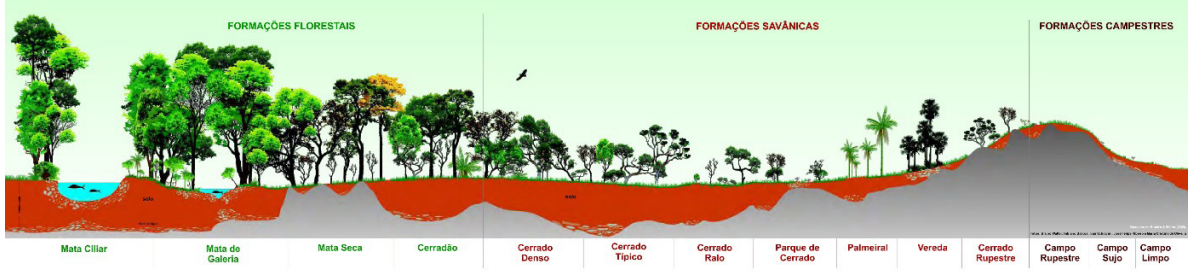

Fonte: Fitofisionomias do Bioma Cerrado. Embrapa. Disponível em: https://www.embrapa. br/cerrados/colecao-entomologica/bioma-cerrado. Acesso em 07 de julho de 2020.

As diferentes fitofisionomias do Cerrado, moldaram os grupos que viviam na região, que tiveram que adaptar suas práticas culturais e aos recursos oferecidos pelo meio ambiente. Posey, que estudou os Kayapó, observou que este grupo foi capaz de fazer o manejo e distribuição de parte das florestas além das suas áreas de formação original. ${ }^{23}$ Os Kayapós transformaram regiões de savanas em terras agrícolas férteis. Isso demonstra que, pelo menos em

\footnotetext{
${ }^{22}$ Os solos sob a vegetação dos Cerrados são Latossolos (46\%) que possuem baixa retenção de água (HOSONO; HONGO, p. 14). Ultisóis (solos argilosos vermelhos) e Entisóis (caracterizados pela ausência ou quase ausência de camadas) também fazem parte da composição do solo do Cerrado, com sérias limitações para a produção agrícola em termos de baixa fertilidade natural do solo. Todos esses tipos de solos são ácidos e apresentam baixa disponibilidade de nitrogênio, fósforo, potássio, cálcio, magnésio, enxofre, boro, cobre, molibdênio e zinco, e apresentam alta saturação de alumínio. SCHEID LOPES, Alfredo. Soils Under Cerrado: A Success History of Soil Management. Better Crops International, vol. 10, no. 2, 1996, pp. 9-15.

${ }^{23} \mathrm{Em}$ uma narrativa vibrante, Posey considerou a criação do apetê como um "processo interessante": "Montes de compostagem são preparados nos apetês existentes a partir de paus, galhos e folhas. Eles podem apodrecer e são espancados com paus para produzir uma cobertura morta. Esta cobertura é subsequentemente levada para um local selecionado no campo e empilhada no chão. Pequenas depressões na superfície são geralmente procuradas porque são mais propensas a reter a umidade. Essas depressões são preenchidas com a cobertura morta, que é misturada com o solo dos montes de um ácaro (Nasutitermes) chamado rorote, e esmaga pedaços do ninho de uma formiga chamada mrum kudja (Azteca sp.). Formigas vivas e cupins estão incluídos na mistura. Os montes resultantes da terra, chamados apete-nu, têm geralmente um a dois metros de diâmetro e 50 a $60 \mathrm{~cm}$. profundo. Os apete-nu são geralmente formados em agosto e setembro, durante as primeiras chuvas da estação chuvosa, e depois são alimentados pelos índios ao passarem pelas trilhas da savana até seus jardins (puru-nu). Ao longo dos anos, o apete-nu 'cresce' em grande apete-ti". POSEY, Darrell. Indigenous Management of Tropical Forest Ecosystems: The Case of the Kayapó Indians of the Brazil Amazonia. Agroforestry Systems, vol. 3, no. 2, 1985. P. 142.
} 
pequena escala, a fertilidade do solo era historicamente possível nas savanas, com o uso do conhecimento tradicional, dos grupos indígenas que ali viviam. Diferentes povos indígenas seminômades também introduziram, disseminaram e domesticaram plantas e animais no Cerrado, como o milho, abóboras, feijões, mandioca e algumas espécies frutíferas. ${ }^{24}$ Esse manejo, porém, era para a prática da agricultura de subsistência, e estavam muito aquém das ambições dos governantes brasileiros e das instituições de pesquisa, que almejavam os solos férteis para a prática das monoculturas em grande escala por todo o Cerrado.

Quando os primeiros grupos de europeus colonizadores iniciaram as tentativas de introdução da monocultura de algodão e milho no Cerrado, eles entraram em contato com grupos que ali viviam e dominavam as técnicas para sobrevivência naquele meio, como pesca, coleta do mel e a utilização de ervas medicinais. ${ }^{25}$ Além disso, desde o século XVIII, a agricultura colonial desenvolveu uma espécie sistema agroflorestal, dividindo espaço com as árvores frutíferas. Os colonizadores misturavam o cultivo de frutas exóticas e nativas, como laranja (Citrus sinensis), banana (Musa), limão (Citrus limon), mamão (Carica papaya), jabuticaba (Plinia cauliflora), jenipapo (Genipa americana), abacaxi (Ananas comosus) e melancia (Citrullus lanatus) com leguminosas, aprimorando as técnicas de fertilização nas suas fazendas. ${ }^{26}$

Segundo Feltran-Barbieri, ${ }^{27}$ alguns outros colonizadores ficaram escandalizados pela maneira "caótica" em que essas plantações foram organizadas, ou seja, havia a policultura e a multifuncionalidade. Estas eram "espécies selvagens e domesticadas, de variedades perenes e permanentes, que acompanhadas de alimentos, como temperos, fibras, corantes, drogas e cosméticos que compartilhavam o mesmo espaço de cultivo, onde espécies de plantas nativas, se misturavam a espécies e exóticas". Desta forma, a vegetação do Cerrado, pode ser avaliada como o resultado de uma interação complexa entre sociedades indígenas e o meio ambiente - que gerenciavam o manejo através dos elementos naturais como fogo, água, flora, fauna, na busca de estratégias alternativas de cultivo naqueles solos.

\footnotetext{
${ }^{24}$ Como pequi (Caryocar brasiliense), murici (Byrsonima crassifólia), buriti (Mauritia flexuosa) e mangaba (Hancornia speciosa).

${ }^{25}$ RIBEIRO, Ricardo Ferreira. Florestas Anãs do Sertão: O Cerrado na história de Minas Gerais. Autentica, 2005.

${ }^{26}$ Ibidem, p. 236.

${ }^{27}$ FELTRAN-BARBIERI, Rafael. Agriculture: Origins of Agriculture in Brazil. Encyclopaedia of the History of Science, Technology, and Medicine in Non-Western Cultures, edit- ed by Helaine Selin, Springer, 2016, p. 2.
} 
Como resultado da expansão transoceânica colonial, esses conjuntos de práticas híbridas surgiram de uma troca de microrganismos, animais e plantas, alguns dos quais prosperaram em no novo meio ambiente ao qual foram introduzidos. A formação de fazendas por volta do século XVII a partir da concessão de sesmarias, trazendo consigo bovinos, equinos, suínos e aves, promoveu também mudanças no tradicional manejo desse ecossistema. 0 emprego do fogo para limpeza da vegetação, onde se aproveitavam as cinzas como fertilizante, incentivando o rebrote do capim nas primeiras chuvas, favorecia algumas espécies mais resistentes ao fogo e ao posterior pisoteio dos animais em detrimento a outras.

Esse manejo também contribuiu para a dispersão de espécies exóticas já naquele período, trazidas, de modo intencional ou não, pelos criadores. Era o caso, por exemplo, do capim-gordura (Melinis minutifloria) nas áreas degradadas, além de outras gramíneas também de origem africana como o capim-colonião (Panicum maximum), capim-angola (Brachiaria miitica) e o capim-jaraguá (Hyparrhenia rufa). Essas gramíneas prosperaram de forma tão intensa na paisagem do cerrado, que se metamorfosearam na paisagem local, tanto aos olhos de alguns botânicos do século XIX, que chegaram a acreditar que tais espécies fossem nativas, como a muitos dos moradores atuais. ${ }^{28}$ Por volta de 1850, os fazendeiros designaram parte de suas áreas de campo para rebanhos bovinos devido à expansão das gramíneas africanas sobre os solos ácidos.

Cada vez mais, a sociedade voltada à pecuária e outros grupos sociais que viviam no Cerrado desenvolveu técnicas para lidar com um ambiente que consideravam inóspito. De fato, nem as altas temperaturas e os meses de muita seca (agosto a novembro), assim como as tempestades durante o inverno, impediram o avanço dos assentamentos dos povoadores, que chegaram após a ocupação dos grupos indígenas. $\mathrm{O}$ avanço da fronteira da pecuária desde $\mathrm{o}$ século XVII moldou cidades, estradas e aldeias. ${ }^{29}$ Além disso, os animais selvagens eram sistematicamente caçados, para não representarem mais perigo para o avanço colonial. A ocupação dessas áreas, incentivadas pelo estado nacional, impulsionou as políticas violentas de negociação, controle e até mesmo extermínio dos povos indígenas, ${ }^{30}$ fornecendo vastas áreas para o avanço do gado e o cultivo agrícola em áreas férteis da floresta.

\footnotetext{
${ }^{28}$ RIBEIRO, op. cit.

${ }^{29}$ MCCREERY, David. Frontier Goiás, 1822-1889. Stanford University Press, 2006, p. 17-20.

${ }^{30}$ GARFIELD, Seth. Indigenous Struggle at the Heart of Brazil: State Policy, Frontier Expansion, and the Xavante Indians, 1937-1988. Duke University Press, 2001.
} 
Solidamente baseados nessa separação territorial entre agricultura e pecuária extensiva, pouco foi investido na infraestrutura para melhorar a produção de alimentos ou agricultura em larga escala. A exploração dos recursos naturais, em geral, foi baseada em técnicas rudimentares e predatórias. A introdução dos arados e outras máquinas tiveram pouco sucesso em algumas regiões brasileiras, ${ }^{31}$ e o cultivo continuou a depender de corte e queima e outras técnicas adotadas desde a chegada dos primeiros colonos. ${ }^{32}$

A ideia de que as técnicas agrícolas eram capazes de melhorar a maioria dos solos do Cerrado, que ainda eram considerados "muito fracos para a agricultura" 33 - não vingou, assim prevalecendo como senso comum, até durante a primeira metade do século XX. Foi após a inauguração de Brasília que a mudança do paradigma interpretativo começou a transformar as terras do Cerrado. $O$ ponto fundamental, relacionado não apenas à percepção geral do uso dessas terras, mas também ao bioma Cerrado como um todo, ocorreu pela primeira vez com a introdução de um referencial de fertilização usado pelas ciências do solo nos Estados Unidos. De 1955 a 1958, um grupo de especialistas em agricultura conectado ao IRI Instituto de Pesquisa (IRI) de Nelson Rockefeller, realizou experimentos relacionados à fertilidade do solo em estufas. Tais experimentos não apenas observaram as deficiências nutricionais desse tipo de solo, mas também avaliaram quais culturas poderiam ser lucrativas nessas áreas: variedades de pasto, arroz, trigo, café, algodão, amendoim, feijão e soja, tornaram-se as colheitas de maior lucro. ${ }^{34}$ As estimativas indicam que até 1970 , cerca de 4,5\% do bioma Cerrado estava sendo explorado para a produção agrícola. ${ }^{35}$ As terras agrícolas expandiram-se para quase $50 \%$ desde

\footnotetext{
${ }^{31}$ HOLANDA, Sérgio Buarque. Raízes do Brasil. Cia das Letras, [1936] 1995.

${ }^{32}$ Em relação ao estado de Goiás durante o século XIX, McCreery escreve: "Enxada, machado, foice e fogo são os instrumentos favoritos de nossos agricultores" (108). Parte do território brasileiro central, particularmente o estado de Goiás, não seguia um padrão de ocupação fronteiriça semelhante ao da "Fronteira Oca". Na visão de McCreery, parecia uma "fronteira de queijo suíço" ou "amontoado de fronteiras". 0 historiador escreve: "Os habitantes de cada vila, fazenda, e fazenda estavam por conta própria no sertão, um "deserto", real ou imaginado, de sede e fome, tempestades violentas e rios inchados, animais selvagens, e bugres"(108), que é uma maneira pejorativa de se referir às populações indígenas brasileiras. Durante os períodos colonial e imperial, em geral, era costume distinguir os indígenas "macios", os integrados à nascente sociedade nacional, em oposição aos indígenas bugres, os indígenas que eram resistentes a esse processo e, por esse motivo, eram considerados "selvagens". Atualmente, bugre é um termo depreciativo usado para se referir a ameríndios.

${ }^{33}$ VIANNA, Oliveira. Populações meridionais do Brasil. Companhia Nacional, [1918] 1933. P. 133.

${ }^{34}$ SILVA, Claiton Marcio da. Between Fenix e Ceres: The Great Acceleration and the Agricultural Frontier in the Brazilian Cerrado. Varia História, vol. 34, no. 65, 2018, p. 413.
}

${ }^{35}$ WALLYS, J. A. N. Intensified Systems of Farming in Tropics and Subtropics. World Bank, 1997. P. 95. 
o desenvolvimento da fertilização do solo com base nas prescrições iniciais do IRI,$^{36}$ no processo chamado de Grande Aceleração. ${ }^{37}$

Em 2010, a influente revista londrina The Economist comentou entusiasticamente o desenvolvimento agrícola do Brasil:

O aumento da produção agrícola brasileira tem sido impressionante. Entre 1996 e 2006, o valor total das culturas do país passou de 23 bilhões de reais (US\$ 23 bilhões) para 108 bilhões de reais, ou 365\%. O Brasil aumentou em dez vezes as exportações de carne bovina em uma década, ultrapassando a Austrália como o maior exportador do mundo. Possui o maior rebanho de gado do mundo, atrás da Índia. É também o maior exportador mundial de aves, cana-de-açúcar e etanol. Desde 1990, sua produção de soja aumentou de apenas 15 milhões de toneladas para mais de 60 milhões. O Brasil responde por cerca de um terço das exportações mundiais de soja, perdendo apenas para os Estados Unidos. Em 1994, as exportações brasileiras de soja foram 1/7 das americanas; agora eles são seis-sétimos. Além disso, o Brasil fornece um quarto do comércio mundial de soja em apenas $6 \%$ das terras aráveis do país.

A abertura do Cerrado brasileiro para a agricultura em larga escala e suas consequências socioambientais teve pelo menos dois momentos decisivos importantes; um científico e um institucional, situado entre a Segunda Guerra Mundial e a Conferência Eco 92. Durante as reuniões acadêmicas sobre pesquisa de solo no início dos anos 1960, os pesquisadores americanos e portugueses do IRI apoiaram a ideia de que essas áreas não utilizadas seriam capazes de suportar uma agricultura intensiva, desde que fossem adotadas práticas aprimoradas de calagem e fertilização. ${ }^{38}$ Adaptando concepções e práticas desenvolvidas durante o New Deal às savanas brasileiras, a pesquisa realizada pela equipe do IRI mudou drasticamente a visão dos agrônomos sobre o solo. Posteriormente, empresários, políticos e agricultores "progressistas" foram convencidos das possibilidades de fertilização - afetando não apenas solos de campos cerrados, mas o bioma Cerrado em geral. Como resultado dos experimentos do IRI com fertilização com cal, nitrogênio, fósforo e potássio

\footnotetext{
${ }^{36}$ SILVA, op cit., p. 419.

${ }^{37} \mathrm{~A}$ Grande Aceleração está relacionada à governança dos ciclos bioquímicos - os ciclos de carbono, enxofre e nitrogênio - intensificados pela ação humana e que formaram um conjunto de processos interligados com consequências globais em relação ao seu impacto no planeta e na biosfera. MCNEILL, John R.; ENGELKE, Peter. The Great Acceleration: An Environmental History of the Anthropocene since 1945. Harvard University Press, 2014.

${ }^{38}$ FREITAS, Luiz M. M. de.; MCCLUNG, Andrew C.; LOTT, Wreal L. Field Studies on Fertility Problems of Two Campos Cerrados, 1958-1959. Ibec Research Institute, 1960.
} 
e micronutrientes específicos, ${ }^{39}$ pela primeira vez, o Cerrado foi considerado fértil e disponíveis para a agricultura em larga escala.

Essas mudanças na concepção dos solos, remodelaram não apenas as terras, mas também o meio ambiente, as sociedades e as prática agrícolas nessas terras. Em 1975, um grupo de especialistas vinculados ao antigo Ministro da Agricultura Alysson Paolinelli, organizou projetos e instituições para o desenvolvimento de áreas do sul de cerrado nos estados de Goiás, Minas Gerais, Mato Grosso e Distrito Federal. Programas e instituições governamentais, como o Polocentro (Programa de Desenvolvimento da Região Centro-Oeste) e a Embrapa (Empresa Brasileira de Pesquisa Agropecuária), juntamente com empresas privadas, adotaram algumas das prescrições do IRI sobre as práticas de fertilidade e apoiaram os projetos com o objetivo de incorporar novas áreas do Cerrado para agricultura e pecuária - especialmente através do uso de fertilizantes com cal e fosfato.

A pesquisa do solo foi institucionalizada com o objetivo de promover a expansão da fronteira agrícola para o Oeste, durante a ditadura civil-militar (1964-1985). o programa de expansão incluía pesquisas contínuas sobre solo, agricultura e pecuária; projetos de ocupação, que incentivaram a migração interna de agricultores do Sul do Brasil (descendentes de alemães, italianos, poloneses e japoneses) e advindos de outros países. ${ }^{40}$ Além disso, financiavam a infraestrutura, como a abertura de novas estradas, desenvolvendo programas de saúde e saneamento e a expansão do sistema educacional.

O agronegócio e seus apoiadores criaram uma nova narrativa que substituiu a visão do Cerrado expressa pelo mito das aventuras do "Cervo Estúpido" e que foi ecoada para todo o mundo com a publicação do artigo na revista Economist, de 2010, com o título de "O milagre do Cerrado". ${ }^{41}$ De acordo com a matéria, o que impulsionou o milagre, foi o ato de conectar o entusiasmo pela ciência com a tecnologia como força motriz para a expansão da fronteira agrícola. Esses elementos foram responsáveis por trazer a fertilidade às terras inférteis, permitindo a expansão das monoculturas.

\footnotetext{
${ }^{39}$ SILVA, op cit., p. 425.

${ }^{40}$ Os "gafanhotos do sul" eram descendentes de colonos japoneses, alemães, italianos e poloneses que eram vistos como agricultores progressistas pelas elites locais e nacionais, e que trouxeram sua experiência agrícola - nas pastagens do Gaúcho e nas florestas do sul, respectivamente - para o Centro-Oeste brasileiro e para a América do Sul. Assim, a fertilização do solo transformou e criou novas hierarquias sociais: os imigrantes do Sul tornaram-se, em duas ou três décadas, a elite do agronegócio no Paraguai, no Cerrado e na floresta amazônica. (Veja SILVA. Op cit, p. 426-30).

${ }^{41}$ The Miracle of the Cerrado: Brazil Has Revolutionised its own Farms. Can It Do the Same for Others? The Economist, vol. 396, no. 8697, 26 Aug. 2010, pp. 50-52. Disponível em: ttps://www.economist.com/ briefing/2010/08/26/the-miracle-of-the -cerrado.
} 
Seguindo esse novo discurso, a alteração nos elementos do solo, levou à exploração econômica de todo o meio natural, alterando o modo de vida dos seres humanos e não-humanos, de forma significativa. 0 padrão de integração do Cerrado a um sistema nacional e posteriormente internacional de produção de alimentos, começou literalmente com a alteração do solo. A grande expansão da fronteira agrícola, após 1950, teve um grande impacto socioambiental. Os solos do Cerrado tiveram que lidar com muitos personagens, que desempenhavam diferentes papéis nesse empreendimento de preparo do solo.

Os pesquisadores se ocupavam com as trocas de conhecimento e os avanços científicos. No solo, eram avaliados a presença ou ausência de micronutrientes, eram introduzidos os fertilizantes, as sementes exóticas, todos esses elementos contribuindo para mudar drasticamente o meio ambiente. Com isso, houve uma crescente perda da biodiversidade e descaracterização desse bioma. O Cerrado foi se distanciando daquela formação florestal narrada nas lendas e conhecida pelos grupos indígenas que ocupavam a região.

\section{O “milagre do Cerrado" em perspectiva crítica}

Na década de 1990, a produção de soja aumentou em todo o Cerrado, novas variedades de grãos foram introduzidas e o gerenciamento da pecuária foi aprimorado. A área de cultivo de soja, milho e algodão no Cerrado aumentou de nove milhões de hectares em 2000-2001 para dezessete milhões de hectares em 2013-2014. A soja como uma única cultura foi responsável por $76 \%$ do aumento total da área de cultivo. ${ }^{42}$ Juntamente com o cultivo da cana-de-açúcar e do milho, essas lavouras, junto da soja, foram responsáveis pela expansão do aumento significativo na aplicação de agrotóxico. ${ }^{43} \mathrm{Além}$ disso, juntamente com a pecuária, impulsionaram o processo de desmatamento, enquanto os agrotóxicos foram responsáveis por poluírem as bacias hidrográficas e aquíferos do Cerrado. ${ }^{44}$ Atualmente, o Cerrado é responsável por

\footnotetext{
${ }^{42}$ CARNEIRO FILHO, Arnaldo; COSTA, Karine. The Expansion of the Soybean Production in the Cerrado: Paths for Sustainable Territorial Occupation, Land Use and Production. INPUT/Agrocoine, 2016. P. 12.

${ }^{43} \mathrm{O}$ efeito residual de pesticidas como o glifosato e o 2,4-D ( $\mathrm{N}$-fosfonometil-glicina e ácido 2, 4-diclorofenoxiacético, respectivamente) nos Ultisoils de Cerrado é mais evidente nas plantas de soja: como o cultivo dessa cultura levou à diminuição no intervalo entre a aplicação de pesticidas e a semeadura de soja, o efeito residual do glifosato e do 2,4-D é maior. PERES-OLIVEIRA, Maria Aparecida et al. Persistence of 2,4-D and Glyphosate in a Cerrado Soil, Brazil. African Journal of Agricultural Research, vol. 11, no. 40, Oct. 2016, pp. 4031-38.

${ }^{44}$ PIGNATI, Wanderlei et al. Spatial Distribution of Pesticide Use in Brazil: A Strategy for Health Surveillance. Ciência e Saúde Coletiva, vol. 22, no. 10, 2017, p. 3290.
} 
$55 \%$ da produção de gado de todo o Brasil e $60 \%$ da produção total de grãos, especialmente milho e soja. ${ }^{45}$

Conforme pesquisadores, associações de pequenos agricultores e ambientalistas, esse desenvolvimento "milagroso" provocou uma degradação ambiental sem precedentes. Um exemplo é a dramática crise hídrica que surgiu no Brasil, em 2014. Embora no campo político se argumente frequentemente que a falta de investimentos das agências públicas causou os problemas de abastecimento, o arqueólogo Altair Sales Barbosa afirma que esse problema é ambiental e maior do que o mensurado, pois se o Cerrado for extinto, levará ao fim de importantes rios de abastecimento e haverá escassez nos reservatórios de água. ${ }^{46} \mathrm{~A}$ formação do Cerrado iniciou-se há milhões de anos e desenvolveu, com o passar dos tempos, uma grande complexidade baseada na forte interdependência entre elementos que compõem esse bioma.

A vegetação do Cerrado depende de solos oligotróficos (com baixos níveis de nutrientes), que dependem de um clima tropical úmido - com duas estações completamente diferentes: seca e chuvosa. Outros elementos moldaram esse ambiente e ainda exercem uma grande influência nas características locais, como o fogo, por exemplo. No entanto, a agricultura extensiva introduziu gramíneas exóticas, da África e da Austrália, que foram preferidas às gramíneas nativas, modificando a estrutura do solo que, por fim, foi o grande causador das erosões. Além disso, pequenas árvores nativas com raízes longas (algumas com até dezoito metros), fornecem uma conexão natural entre chuva e as fontes de águas subterrâneas. Com a derrubada dessas árvores e com as monoculturas, houve a interrupção desse complexo processo. A exemplo, pode-se citar as plantas de soja, que não conseguem fazer a água da chuva penetrar no solo, ao invés disso, a água flui sobre a terra, aumentando a erosão e causando inundações. ${ }^{47}$

Também, o bioma Cerrado possui a menor porcentagem de áreas com Unidades de Conservação (UC) de todos os hotspots do mundo. ${ }^{48} \mathrm{O}$ Ministério do Meio Ambiente do Brasil tem atualmente o registro de apenas dez unidades

\footnotetext{
${ }^{45}$ DE PAULA, Laura. Cerrado é campeão de produtividade na agricultura. Revista Safra, 11 Sep. 2013, http:// revistasafra.com.br/cerrado-e-campeao-em-produtividade-na-ag-ricultura/.

${ }^{46}$ BARBOSA, Sales. O Cerrado está extinto. Interview with Marcelo Gouveia. Jornal Opção, 10 abril de 2014, http://www.jornalopcao.com.br/entrevistas/o-cerrado-esta-extinto-e -is- so-leva-ao-fim-dos-rios-e-dos-reservatorios-de-agua-16970/.

${ }^{47}$ Ibidem.

${ }^{48}$ As áreas de conservação no Cerrado existem desde 1959: primeiro, o Parque Nacional Araguaia, cobrindo dois milhões de hectares, seguido pela criação de três novos parques em 1961, que expandiram a área protegida para aproximadamente 2,8 milhões de hectares (GANEN et al, 2013, p. 102).
} 
alocadas no Cerrado. ${ }^{49}$ Houve uma estratégia de criação de algumas Unidades de Conservação, mas não houve a preocupação na manutenção dos corredores ecológicos, o que resulta na impossibilidade de recuperação ambiental, isolando as UCs em ilhas, cercadas pelo oceano de plantações e cidades. As Unidade de Conservação atualmente, ocupam uma área de apenas $4,4 \%$ do bioma. ${ }^{50}$

As crescentes críticas dos movimentos ambientalistas e sociais ao processo de desmatamento no Brasil, no final dos anos 1980 e início dos anos 1990, especialmente no contexto da Conferência Eco'92 do Rio de Janeiro, introduziram um ponto de vista diferente no debate sobre o Cerrado. Se, entre as décadas de 1950 e 1970, a crença na ciência agrícola e no desenvolvimento econômico ofuscou as críticas às possíveis degradações ambientais, isso vem mudando desde o início dos anos 1990, devido à contínua expansão do agronegócio e aumento significativo de danos ao meio natural..$^{51}$

De acordo com McNeill e Winiwarter, "por falta de nitrogênio, muitos reinos foram perdidos", ${ }^{52}$ no caso do Cerrado, povos indígenas, camponeses sem terra e pequenos agricultores estão vendo seus ex-modestos "reinos" declinarem pelas mãos do agronegócio. Como explica a teoria da diversidade biossocial de Beinart, ${ }^{53}$ a crescente invasão das terras dos povos indígenas e a destruição de seus modos de vida se correlacionam com o desmatamento. ${ }^{54}$ Durante o governo do Partido dos Trabalhadores (2003-2016), ambos os presidentes que governaram o país, advogaram em prol de políticas públicas para estimular a manutenção ou aumentar o número de áreas designadas para as populações tradicionais no Cerrado. Como resultado, durante o primeiro semestre de 2010, o nível de desmatamento diminuiu ligeiramente em comparação com as estatísticas das últimas duas décadas. ${ }^{55}$

\footnotetext{
${ }^{49}$ Disponível em: https://www.icmbio.gov.br/portal/unidadesdeconservacao/biomas-brasileiros/cerrado/ unidades-de-conservacao-cerrado. Acesso em 09 de julho de 2020.

${ }^{50} \mathrm{As}$ unidades estaduais de conservação (uso totalmente protegido e sustentável) representam mais de nove milhões de hectares, ou $4,4 \%$ do bioma. As unidades totalmente protegidas somam apenas 1,8 milhão de hectares (0,9\%), enquanto as unidades de uso sustentável cobrem 3,6\%. Os totais de 167 unidades de conservação federais e estaduais compreendem $3,1 \%$ e 5,2\% do bioma, respectivamente. A área total dessas unidades é de 8,3\% do bioma (GANEN et al, 2013, p. 102).

${ }^{51}$ Ver DEAN, op. cit.

${ }^{52}$ MCNEILL, John R.; WINIWARTER, Verena. Soils and Societies: Perspectives from Environmental History. The White Horse Press, 2010. P. 2.

${ }^{53}$ BEINART, op cit.

${ }^{54}$ Sobre este tópico, consulte o estudo de caso de Gomide e Kawakubo, para obter detalhes sobre a expansão da soja nas terras indígenas dos Xavante. GOMIDE, Maria Lúcia; KAWAKUBO, Fernando Shinji. Povos indígenas do cerrado, territórios ameaçados: terras indígenas Xavante de Sangradouro/ Volta Grande e São Marcos. Agrária (São Paulo. Online), no. 3, pp. 16-46.
}

${ }^{55}$ CRITICAL ECOSYSTEM PARTNERSHIP FUND, op cit. 
No entanto, o controverso processo político que resultou no impeachment da presidenta Dilma Rousseff em 2016, fortemente apoiado pelos defensores do agronegócio, está trazendo de volta um aumento na expropriação e desmatamento de terras. Devido a esse processo, a campanha eleitoral de 2018 trouxe de volta a retórica dos candidatos conservadores comprometidos a diminuir o número de terras protegidas para uso pelas populações tradicionais. A mesma postura foi vista dentro do Ministério do Meio Ambiente, a partir dos posicionamentos do ministro Ricardo Salles, que de forma escancarada vem desmontando a agenda verde em favor do agronegócio. ${ }^{56}$

Por sua vez, esses posicionamentos intensificaram os movimentos de resistência. A "Carta dos Povos Indígenas do Cerrado e da Caatinga" e a "Declaração dos Direitos dos Povos e Comunidades Tradicionais do Cerrado Brasileiro" foram escritos ainda em 2018, acusando o agronegócio internacional de causar conflitos agrários no Brasil. ${ }^{57}$ Enquanto isso, o Brasil continua sendo o país mais violento do mundo em termos de líderes ambientais assassinados, uma parte significativa deste problema está relacionada ao avanço da fronteira agrícola. ${ }^{58}$ Ainda, o mercado global de commodities, no caso do Cerrado, tem efeitos negativos no dia a dia das pessoas.

Pequenos agricultores e pobres habitantes dos centros urbanos dependem do meio ambiente para aumentar a disponibilidade de alimentos e para sua subsistência. Em nossa vivência na região pudemos perceber que a maioria dos grupos sociais que vivem nessas áreas depende ainda da complementação alimentar advinda da horticultura e da coleta. Os frutos nativos do Cerrado fazem parte da dieta cotidiana. A exemplo, cita-se o pequi e o buriti, frutas que mesmo ameaçadas com o aumento do desmatamento, ainda estão presentes nos pratos elaborados na região e são responsáveis pelo complemento nutricional de muitas famílias. Em algumas áreas rurais, os pequenos agricultores geralmente misturam uma pequena porção de farinha de mandioca caseira com café; esse líquido faz a farinha se expandir dentro de um copo, como um pequeno bolo. Para muitos povos indígenas e camponeses, essa é a

\footnotetext{
${ }^{56}$ Como Ricardo Salles tem desmontado a agenda verde em favor do agronegócio. Época, 09 de maio de 2019. Disponível em: https://epoca.globo.com/como-ricardo-salles-tem-desmontado-agenda-verde-em-favor-do-agronegocio-23652038. Acesso em 09 de julho de 2020.

${ }^{57}$ Originalmente intitulado: "Carta dos Povos Indígenas do Cerrado e da Caatinga: Desafios para a Gestão Ambiental e Territorial das Terras Indígenas" e "Declaração sobre os Direitos dos Povos e Comunidades Tradicionais do Cerrado Brasileiro".

${ }^{58}$ Global Witness. Defenders of the Earth: Global Killings of Land and Environmental Defenders in 2016. Global Witness, 2017, p. 6. Disponível em: www.globalwitness.org/en/campaigns/environmental-activists/ defe nders-earth/
} 
refeição mais substancial ou mesmo a única alimentação diária. Em resumo, o ambiente, que é provedor (ou pelo menos uma fonte parcial) de alimento para muitos grupos sociais, está sendo perigosamente desconfigurado.

\section{Considerações Finais}

A história da grande transformação do Cerrado brasileiro começa desde a profunda convicção de que os solos daquele bioma eram inférteis, devido à acidez excessiva. Posey demonstrou, por outro lado, que as populações tradicionais brasileiras já possuíam técnicas complexas de fertilização, capazes de transformar áreas de savana, com solos ácidos, em sistemas agroflorestais.

As pesquisas e experimentações nos solos do Cerrado tiveram um impacto significativo nas instituições, no meio ambiente e na cultura nacional. A importância de estudar este bioma está calcada no fato de que o Cerrado passou por uma transformação rápida e intensa, que iniciou no solo, através de políticas públicas e incentivos governamentais e acabou transformando o cotidiano dos grupos sociais que vivem naquela região.

Mudanças na percepção sobre os solos do Cerrado modificaram os padrões de uso e de intervenções gerais no bioma. Mais do que isso, está transformando a maneira como as elites e os governantes do agronegócio interpretam suas terras inférteis em todo o mundo. Os solos foram fertilizados para aumentar a produtividade, acelerar ganhos com a produção de monoculturas em larga escala. Segundo as narrativas do agronegócio, a experiência no Cerrado permitiu ao Brasil desenvolver "uma agricultura de precisão", onde os problemas ambientais seriam minimizados com a incorporação da região na economia global.

A experiência no desenvolvimento da fertilidade do solo e a introdução de novas espécies vegetais geraram, nesse sentido, um instrumento tecnológico de referência, exportado para outros ecossistemas em diferentes partes do mundo: Indonésia (na década de 1980), El Salvador (década de 1990), assim como experimentos também estão sendo aplicados no Paraguai, na Colômbia, e atualmente nas savanas da África. Esse modelo de fertilização, para terras com alta acidez, modificou ambientes em várias regiões do globo terrestre, desde a década de 1970. Como o modelo de fertilização foi exportado para outros continentes, o Cerrado tornou-se global. Alguns elementos ainda são específicos do Cerrado, principalmente quando se foca para estrutura 
social, como a existência de elites regionais e a permanência de uma estética regionalista..$^{59}$

A expansão agropastoril impulsionou os mercados de alimentos, proporcionando estabilidade alimentar e preços mais adequados para os consumidores locais. No entanto, a disponibilidade de milho, soja, feijão ou carne bovina tem sido mais conectada aos mercados nacionais e globais, tornando o expansionismo agrícola do Cerrado um processo histórico muito dramático, que envolve degradação ambiental em escala inenarrável. Assim, a diminuição das áreas de reservas indígenas, dos quilombolas e das terras comuns, levou a um declínio no suprimento de alimentos para sertanejos, indígenas e locais que dependiam das zonas florestas e campos para coleta e produção de alimentos. $O$ avanço de uma visão crítica da agricultura industrial e suas consequências como, a violência, a perda de fontes de alimentos e o aumento de problemas de saúde relacionados ao uso de agrotóxicos, está confrontando as elites do agronegócio.

Artigo recebido para publicação em 30/07/2020

Artigo aprovado para publicação em 17/11/2020

\footnotetext{
${ }^{59}$ Como o historiador brasileiro Albuquerque Júnior apontou, em vez de abraçar os ideais europeus de modernização, durante a primeira metade do século XX, as elites locais do nordeste do Brasil criaram um padrão cultural ao misturar a estética rural / tradicional com os ideais modernos. O padrão das elites centro-ocidentais é muito semelhante. ALBUQUERQUE JUNIOR, Durval Muniz de. A invenção do Nordeste e outras artes. Recife: FJN: Ed. Massangana; São Paulo: Cortez, 2009.
} 